\title{
Eliminate obstacles of use the solar systems as buildings facades using multilayers optical interference filters
}

\author{
Zainab I. AL-Assadi *, Fawzia Irhayyim AL-Assadi**, Ban M. Alameri*** \\ *Department of Physics, College of Science, Mustansiriyah University, Baghdad, Iraq \\ Zainab I. AL-Assadi : dr.zainabrhm@uomustansiriyah.edu.iq \\ **Department of Architecture, college of Engineering, Baghdad University, Baghdad, Iraq \\ Fawzia Irhayyim AL-Assadi: fawziaasadi@coeng.uobaghdad.edu.iq \\ ***Department of Electrical, college of Engineering, Mustansiriyah University, Baghdad, Iraq \\ Ban M. Alameri : Ban.alameri@uomustansiriyah.edu.iq \\ **Author for Correspondence: Fawzia Irhayyim AL-Assadi \\ fawziaasadi@coeng.uobaghdad.edu.iq
}

\begin{abstract}
The Building design in a correct way and totalitarian requires integration of using solar energy technologies in the architectural design stage of the roofs and facades as the most appropriate places to obtain solar energy because it greatly affects the architectural aesthetic. This integration has to be taken into account at the design stage, which leads to effective and attractive solutions. Architecture needs the energy to complete its functions to increases human effectiveness and ability to do its tasks better, solar energy is the main factor of providing the necessary energy due to its abundance as well as being clean energy and does not cause polluting emissions to the environment. To provide a comfortable indoor environment for the occupants, Solar Thermal Collectors (STC) and Photovoltaics Cells (PV) used, which convert solar energy into thermal energy and electrical energy, respectively. The main problem of this study is concerning with the problems of the black color, visible tubes, metallic strip gradients (absorption strip), and welding points of the solar systems which gives the facades of the buildings an undesirable view and weakens the aesthetic aspect of the buildings and limits the abilities of architects to use because of their black color and undesirable aspect.

The aim of this study is a design of optical interference filter (multilayer coatings) prepared by RF magnetron sputtering as a solution to the problem of black color, visible tubes, metallic strip gradients (absorption strip), and welding points in solar thermal collectors and photovoltaic cells, which are the main reasons for not using solar systems as building facades, this technique works to increase the efficiency of the solar systems and increase the amount of clean energy generated, also enhancing the expressive and aesthetic aspect of facades of buildings. In the NIR region this filter works as an anti-reflective coating. Also the coating includes a high color reflection at a certain wavelength in the VIS region to give the solar system an aesthetic feature, which is used as building facades by using appropriate dielectric substances with high and low reflective indexes likes $\mathrm{SiO} 2$ and $\mathrm{MgF} 2$ respectively. The results of the study showed that the increase in the number of layers will lead to an increase in the visible reflectivity peak, while near of infrared region remains an anti-reflective with a high Transmission of solar rays, thus increasing solar systems efficiency.
\end{abstract}

Keywords. Solar systems, building facades, Thin films, Architecture, Physics.

\section{1- Introduction}

Optical coatings can provide very attractive colors that increase the aesthetic aspect of buildings, while the traditional systems with black color that limiting the architectural and aesthetic capabilities of building facades. These colors arise from the effect of interference that enhance the reflectivity or 
Transmission in specific parts of the VIS spectrum and hide them in the other regions. also, the required spectral properties can be obtain by design this coatings. [1,2]

The technique of create the desired color is based on an optical interference filter (multilayer coating), and a large model of colors can be obtained by changing the thickness or number of layers. [3]

The idea of using colored glazing for glass for covering solar cells systems, which includes solar thermal collectors and photovoltaic cells that are used as buildings facades, was reached by depositing thin film of multilayer on the glass surface of the solar systems.

The reflectivity ideal of a glass film system should be a narrow beam of VIS light, while the remaining part of the solar light focused towards to a solar system (the black absorber of the solar collector if it use or on a solar cell) to reduce energy loss, as shown in Fig. 1. [4].

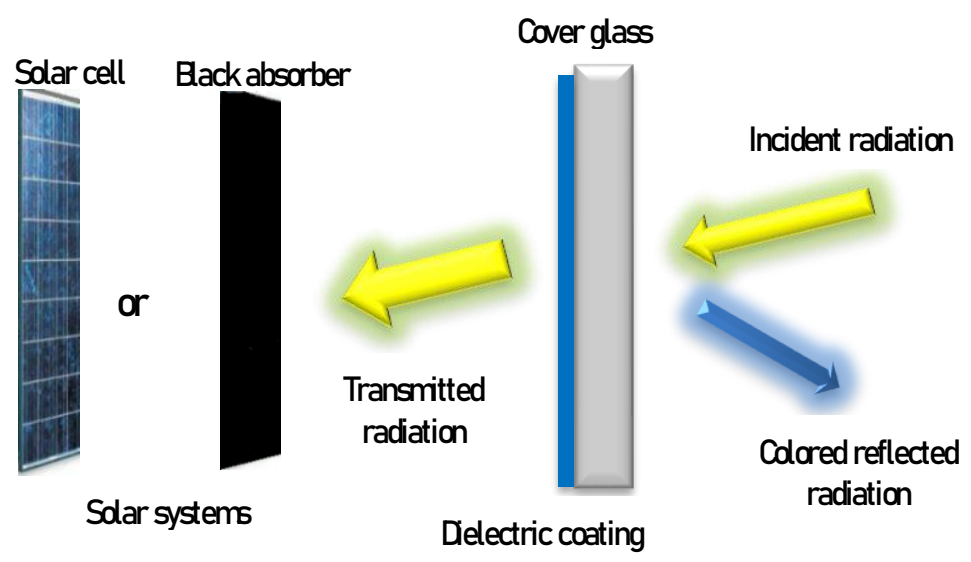

Fig.1. Mechanism of Coloring solar systems - Researcher

One part of the solar energy of VIS spectrum is invested to make the solar system as a building's facade more beautiful by having other colors, and the other part of the spectrum, which represents most of the energy, will pass in a solar system and will be absorbed and converted into heat in the black surface, with this way the using solar collectors or converting to electrical energy if the solar cell was used and will feed the building as seen in Fig. 2. [5]

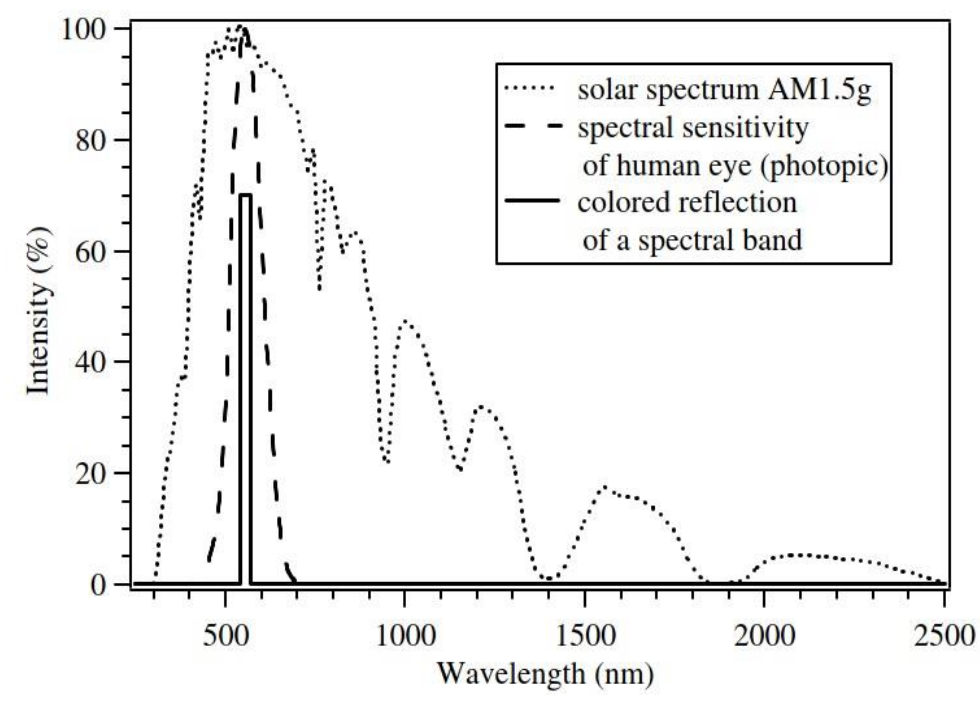

Fig. 2. The reflection of a narrow band in VIS range [5]. 
The requirements to achieve the highest colored reflection from the multi-layers that consist of oxides of materials are:

First: A large amount of solar radiation energy must pass through the coatings.

Second: The need for materials with zero absorbance or approximately zero to avoid energy loss within the coating.

Third: Stability of colors which is depending on changing the reflection angle.

Finally, The narrow peak of reflectivity in the VIS region, which fixes the desired color of the reflected light. To obtain colored reflected light, the solar systems cover glass must be coated on one or both sides with thin films. To avoid any absorption, these thin films must be made of transparent and insulating materials such as $\mathrm{TiO}_{2}, \mathrm{Al}_{2} \mathrm{O}_{3}, \mathrm{SiO}_{2}, \mathrm{MgF}_{2}$, or a combination of these oxides.

Glass manufactured in the world is supplied with anti-reflective coatings and optical filters for thermal control or decorative coatings. In architecture, large panels of glass are used as building facades in commercial buildings and glazing in residential buildings for daylighting [6].

\section{2- Reflectivity of Thin Films}

When designing multi-layer optical coatings, the refractive index and thickness of each layer have to determine according to specifications for spectral reflectance [7].

If the optical thickness is an integral number of a quarter-wave or half-wave, the thin-film characteristic matrix takes a very simple form as below;

If $m$ is an even number, then

$$
\Phi=m(\pi / 4) \quad m=0,1,2,3, \ldots .
$$

$$
\cos \Phi= \pm 1 \quad \text { and } \quad \sin \Phi=0,
$$

so that a layer is an integral number, its thickness equal half wavelengths, and the matrix becomes:

$$
\pm\left[\begin{array}{ll}
1 & 0 \\
0 & 1
\end{array}\right]
$$

This is a unity matrix that does not affect the reflection or Transmission through the layers. In the case of $\mathrm{m}$ is an odd number,

$$
\sin \Phi= \pm 1 \quad \text { and } \quad \cos \Phi=0,
$$

so that the layer is an odd number of quarter wavelengths, and becomes the matrix [8].

$$
\pm\left[\begin{array}{cc}
0 & i \\
i \xi & 0
\end{array}\right]
$$

By numerical simulation the thin-film filters optical properties can be calculated using the complex matrix multiplication method, where the characteristic matrix represents each layer which can be described as below

$$
\left[\begin{array}{l}
X \\
Z
\end{array}\right]=\prod_{r=1}^{q} M_{r} \cdot\left[\begin{array}{c}
1 \\
\xi_{s u b}(\lambda)
\end{array}\right]
$$

Where equation (1) is called the system matrix, the optical permittivity of the electromagnetic waves parallel components incident at the outer surface is given by the relationship:

$$
Y(\lambda)=H(\lambda) / E(\lambda)=X / Z
$$

Where:

$\mathrm{M}_{\mathrm{r}}$ : the characteristic matrix for each layer,

$\xi_{\text {sub }}(\lambda)$ : the optical Permeability of the base, and (q): layers number in the packet.

It assumes little absorption, which is consistent with the requirements for approximately zero absorption if the dielectric coating materials used. The reflectivity is given by in equ. (2)

While Transmission is given by equation (3)

$$
\rho(\lambda)=\left(\frac{\xi_{0}(\lambda)-Y(\lambda)}{\xi_{0}(\lambda)+Y(\lambda)}\right)^{2}
$$




$$
\tau(\lambda)=\frac{4 . \xi_{0}(\lambda) Y(\lambda)}{\left(\xi_{0}(\lambda)+Y(\lambda)\right)^{2}}
$$

Where $\xi_{0}(\lambda)=1$ for air, which is the incident medium.

For zero-absorbed mediums, the equation of energy conservation is:

$$
\rho+\tau=1
$$

Equation (4) is used for spectral values and integral quantities, such as $\tau_{\text {sol }}$ or $\rho_{\text {vis. }}, \tau_{\text {sol }}$ is defined as the ratio between an incident and transmitted solar radiation, while $\rho_{\text {vis }}$ is defined as the ratio between an incident and reflected daylight (CIE D65) referred to as the optical efficiency function $V(\lambda)$ of the human eye. [9]

The angular dependence inherent in multilayer planar packets is due to the complex interactions in these multilayer thin films. High color saturation and at the same time high Transmission can be achieved by a narrow reflection peak. To protect the functional layer from the effects of conditions weather, it is applied to the back surface of the glass cover of the solar panel, which can be manufactured by spattering coating technique [10]

The reflected beam can be formed when all the multiple beams emerge from the upper surface when the wavelength is quarter-wave and the interference the greatest value. The width of the high reflection region is restricted, if the refraction coefficient is high, the region is wider.

The layer design wavelength becomes half-waves, so the effects of their interference disappear. In this case, the insulating substrate (base) is also coated with thin films of dielectric material, which support interference of multiple-beam [8] as shown in Fig. 3.

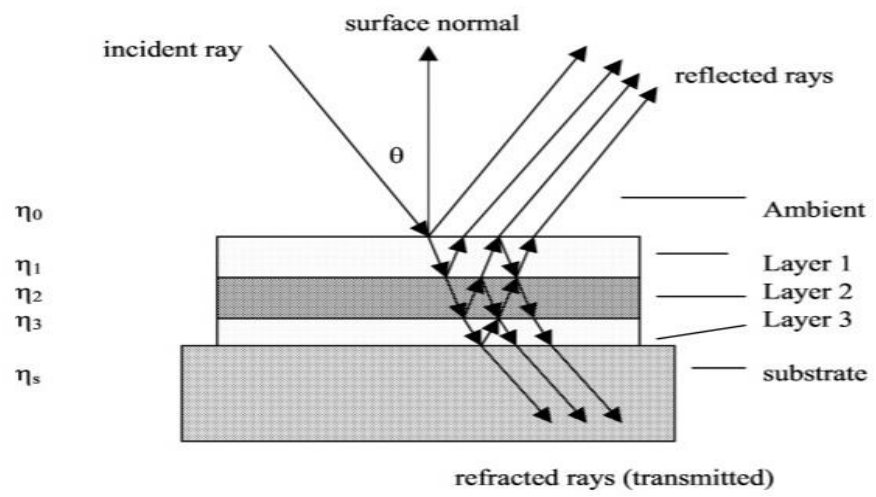

Fig. 3. Cross-section of the Multilayer thin film system. [11]

\section{Architectural and physical aspects of solar systems as building facades}

Solar systems can be used in facades as an aesthetic element in the building's design due to the difference of type and color of the covers solar systems, which by changing their color can change the appearance of the facade and be integrated with facades, not only on the roofs of buildings, as in Fig. 4. [16] 


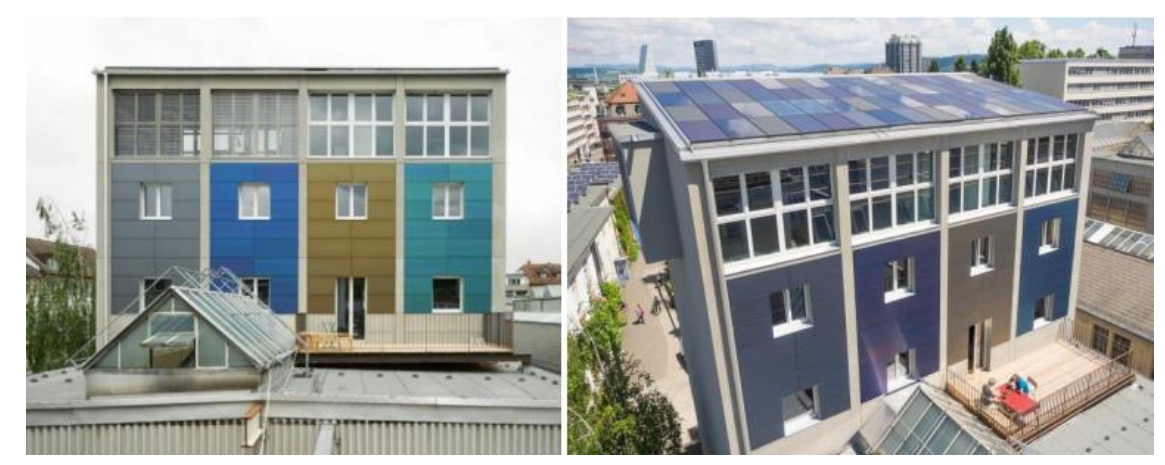

Fig. 4. Colored solar panels as facades [17].

Fig. 5. shows the Trifolium building in Copenhagen which originally designed in 1966, which is covered with thermal solar collectors recently. This technique is used to cover the facades with colored glass, furthermore, the glass acts as a solar collector to provide thermal energy for the building.

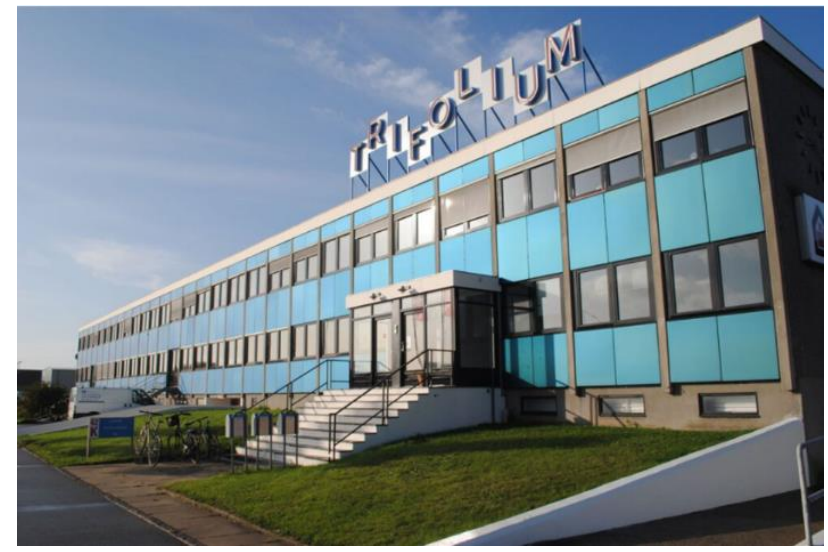

Fig. 5. Trifolium Office showing the distribution of glazed solar thermal collectors in bluish green [16].

south and west oriented in addition to using STC as multifunctional elements facade sheathing, also can be used as balcony baluster as in Fig. 6 .
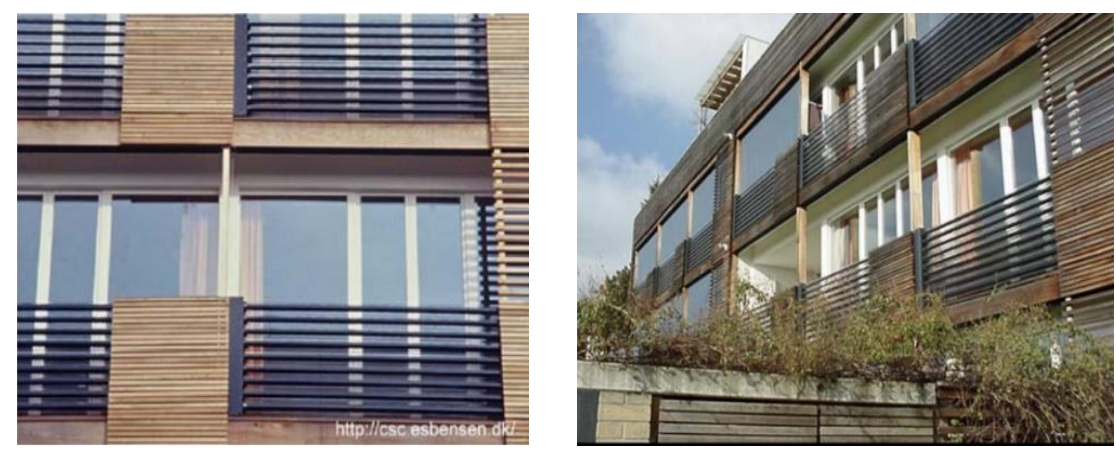

Fig. 6. Solar collectors used as baluster balconies [15] 


\section{The practical part of the study}

In this study, an optical coating with high (green) color reflectivity, the wavelength (558) $\mathrm{nm}$ in the visible region, and anti-reflectivity near-infrared region were obtained by designing the Air//LH//Glass optical model for layers of thickness quarter-wave.

A layers with a high refractive index $(\mathrm{H})$ were used, materials a low refractive index $(\mathrm{L})$ to produce multi of layers LHLHLHLHLH, for an even layers of (2-8) which are dielectric materials like silicon dioxide $\left(\mathrm{SiO}_{2}\right)$, also known as silica with (1.47) refractive index, and magnesium fluoride $\left(\mathrm{MgF}_{2}\right)$ with (1.38) refractive index. These materials were deposited on a glass substrate having a refractive index (1.5131) by using RF-CoMagnetron sputtering (CRC-600).

The difference between the high and low refractive index of materials controls the peak of the reflectivity curve [18]. If the difference between the refractive indexes is high, the spectral region with a high reflectivity [19],[20].

The study is interested in a narrow peak of reflection, which can be formed mainly by employing a large number of layers about (8) layers, and materials chosen to have an approximate refractive index, and non-identical, because the reflection at the surface is weak.

\section{5- Results and Discussion}

It seen from the results of the multilayers containing $\mathrm{SiO}_{2}$ with a thickness of (94.89) $\mathrm{nm}$, and $\mathrm{MgF}_{2}$ with a thickness of (101) nm, which were deposited to two layers of $\mathrm{SiO}_{2}$ and $\mathrm{MgF}_{2}$ respectively for (8) layers, the increasing of layers' number to an even number of (2-8), will lead increasing reflectivity peak height in the visible region, while the region near-infrared remains an anti-reflective region, as shown in Fig. 7.

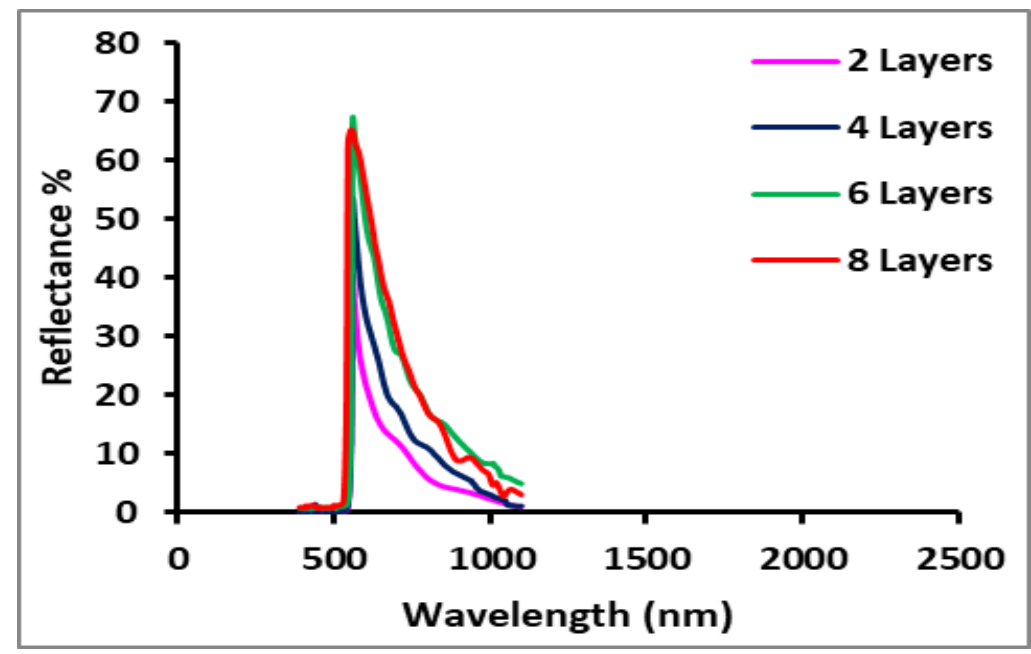

Fig. 7. (2-10) multilayer thin films reflectivity spectrums curve. Researcher

Table (2) show the experimental results, where the reflectivity peak of the visible region for two layers is $(40.084 \%)$, and it increases with an increasing number of layers until reaching the eighth layer, the reflectivity peak in the visible region $\rho_{\max }(73.879 \%)$, it represents a high optical coating efficiency of the eight layers.

While for the solar reflectivity $\rho_{\mathrm{sol}}$, represents the amount of reflected part of the solar radiation outside the solar system, as the amount of solar radiation loss reaches its highest value at the eighth layer $(15.4582 \%)$ which is a small amount, so the near-infrared region will remain an anti-reflective region.

Table 1. (2-10) multilayer thin films optical properties- Researchers 


\begin{tabular}{|c|c|c|c|}
\hline $\begin{array}{c}\text { No. of } \\
\text { layers }\end{array}$ & $\boldsymbol{\rho}$ max.\% & $\boldsymbol{\rho}$ sol.av.\% & $\tau$ sol.av.\% \\
\hline $\mathbf{2}$ & 40.084 & 5.42518 & 94.55082 \\
\hline $\mathbf{4}$ & 53.395 & 9.055929 & 90.90656 \\
\hline $\mathbf{6}$ & 68.363 & 15.03945 & 84.88024 \\
\hline $\mathbf{8}$ & 73.879 & 15.4582 & 84.45467 \\
\hline
\end{tabular}

The transmittance solar represents $\tau_{\text {sol }}$, the amount of solar radiation transmitted into the solar system, which causes heating of water or air if used a solar thermal collector, and causing an electrical energy generation if used solar photovoltaic energy.

From the results in a table (1), it is found that the value of solar transmittance is high at two layers of $\left(\mathrm{SiO}_{2}\right.$ and $\left.\mathrm{MgF}_{2}\right)$ and reaches $(94.55082 \%)$, while its value decreases due to the presence of the reflectivity which increased with the number of layers, where the solar transmittance value was less in the eighth layer (84.45467\%), and this value confirms that coating has high coloring efficiency and good energy efficiency. More than $85 \%$ of architects prefer other colors instead black this is showed by the recent survey, even it is less efficient [11].

The coating used shows a green color reflection, which will add an aesthetic value to the solar systems as the thermal solar collector or solar photovoltaic panels, which can be as buildings facades, while the near-infrared region remains an anti-reflective with high transmittance of solar radiations, and that leads to an increase in efficiency of solar systems.

\section{Conclusions}

In the study, by using Co-magnetron sputtering to manufacture multi-layer coating, is achieved:

1- An absorption is approximate to zero, the absorption loss has been eliminated, by using dielectric materials in the multi-layer coating, and thus improve solar system efficiency.

2- A green color reflection peak in the visible region of the multi-layered optical coating gave the architect flexibility of design by integrated the solar collectors or glazed solar as facades, which were limited in black color, as well as the visible details of the solar system such as tubes, welding points, and absorption slide.

3- Good solar transmittance that reached $94.5 \%$ at the second layer, and increasing with the number of layers to reach $84.45 \%$ at the eighth layer.

4- The design and manufacture coatings of multi-layer colored optical is the task of the physicist, and the choice of the number of layers and the color degree depends on the vision of the architect and the function of the building, whether the building needs a large proportion of the solar radiation, or moderate degree of penetrating, it is sufficient to supply electrical energy used for heating and cooling when used solar collectors, and can use the solar cells to feed lighting and other purposes of building.

\section{Recommendations}

- Study for Introducing new methods of construction adopting solar architecture and focusing on effective systems in the building's design, and developing and integrating solar systems with buildings, which is considered the first step of new generation buildings that integrated solar systems in building materials design of the roof and facades.

- It is important to understand the solar energy potential for architects in the design stage, and the integration of solar energy in the building with the roofs and facades leads to effective and attractive solutions and must be carefully considered for its great effects on architecture. 
- Replacing traditional façade building materials with solar modules, is economic because the additional cost to install the solar system is low to the total construction cost and cheap per square meter.

- Possible further researches are to analyze new materials other than those used in this study, by designing new samples to obtain different coatings and colors.

- New analyzing method by changing the central wavelength $\left(\lambda^{\circ}\right)$, not used in this study, such as changing the thickness of the layers and observing the color resulting from using more than two coating materials.

\section{Acknowledgments:}

The authors express their gratitude to the University of Baghdad, Ministry of Science and Technology, and Mustansiriyah University in Iraq for supporting this study.

\section{References}

[1] Macleod, H. A., 2007. Optical Thin Film. Optical Sciences Opti 575, Thin Film Center Inc. 2745 East via Rotonda Tucson, AZ 85716-5227, pp. 14-18, USA.

[2] Wyszecki, Günter and Styles, W. S. 1982. Color science (2nd Ed.). New York: John Wiley \& Sons. [3] Munari Probst, M. C., Schuler, A., and Roecker, C., 2010. "Bringing Colours to Solar Collectors: A Contribution to an Increased Building Integrability." CH-1015 Lausanne, Switzerland.

[4] A. Schüler 2004. "International Patent Application", WO 2004/079278, published on 16.09.2004.

[5] Schüler, A., Roecker, C., Boudaden, J., Oelhafen, P., and Scartezzini, J. L.Potential of quarterwave interference stacksfor colored thermal solar collect, Solar Energy 79 (2005) 122-130.

[6] Mertin, V., Hody - Le Caër, Joly, M., Scartezzini, J. L., and Schüler, S. A. 2011. "Coloured Coating for Glazing of Active Solar Thermal Facades by Reactive Magnetron Sputtering", clean tech for sustainable buildings from Nano to Urban Scale, solar energy and building physics laboratory, Vol. 1, pp. 31-36, Lausanne, Switzerland.

[7] Nakamura M, Kobayashi K, Kobayashi M (2002) Optical Multilayer Coating Synthesis by Simultaneous Optimization of Number of Layers, Refractive Index, and Thickness. In: Inverse Problems in Engineering Mechanics III. Elsevier, pp 311-314

[8] Macleod HA (2017) Thin-film optical filters. CRC press.

[9] Mertin S, Muralt P, Scartezzini J-L Potential of magnetron sputtered magnesium fluoride containing thin films for the multilayer design of coloured coatings for solar collector glazing. In: Proceedings of International Conference CISBAT 2015 Future Buildings and Districts Sustainability from Nano to Urban Scale, 2015. vol CONF. LESO-PB, EPFL, pp 21-26

[10] Bläsi B, Kroyer T, Höhn O, Wiese M, Ferrara C, Eitner U, Kuhn TE Morpho butterfly inspired coloured BIPV modules. In: 33rd European PV Solar Energy Conference and Exhibition, 2017. pp 2529.

[11] Weiss, W., and Stadler, I. 2001. "Facade Integration - A New and Promising Opportunity for Thermal Solar Collectors." In: Proceedings of the Industry Workshop of the IEA Solar and Cooling Programme, Task 26 in Delft, The Netherlands.

[12] Salu, Y. 2008. Physic and Architects (2nd Ed.). Howard University, Washington D.C., USA.

[13] Schüler, A., Roecker, C., Scartezzini, J. L., Boudaden, J., Videnovic, I. R., Ho R. S. C., and Oelhafen, P. 2004. "Interference Filters for Colored Glazed Thermal Solar Collectors." Solar Energy Materials and Solar Cells 84: 241-254

[14] Buker, Mahmut Sami \& Riffat, Saffa B., "Building integrated solar thermal collectors - A review", Renewable and Sustainable Energy Reviews, Volume 51, November 2015,p. 327-346.

[15] Maria, Cristina \& et al, "DESIGNING SOLAR THERMAL SYSTEMS FOR ARCHITECTURAL INTEGRATION", 2013, p.36 
[16] https://www.swissinso.com/projects

[17] Eder, Gabriele \& et al, "COLOURED BIPV Market, Research and Development", Report IEAPVPS T15-07: 2019, February 2019m p.26.

[18] Wasa, K., Kitabatake, M.,and Adachi, H. 2004."Thin Film Materials Technology: Sputtering of Compound Materials.” Yokohama City University, Yokohama, Japan.

[19] Schüler, A., Roecker, C., Boudaden, J., Oelhafen, P., and Scartezzini, J. L. 2003. "Coating for Coloured Glazed Thermal Solar Collectors and Solar Active Glass Facades.” EPFL, Lausanne, pp. 335340.

[20] Schuler, A., Boudaden, J., Oelhafen, P., De E. Chambrier, E., Roecker, C., and Scartezzini, J. L. 2005. "Thin Film Multilayer Design Types for Colored Glazed Thermal Solar Collectors." Solar Energy Materials and Solar Cells 89: 219-231. 